\title{
Família, religiosidade e identidade étnica nas práticas de transmissão de nomes de batismo em um grupo de imigrantes italianos
}

\author{
Fábio Augusto Scarpim*
}

O presente artigo tem como objetivo analisar a construção da identidade etnocultural de um grupo de imigrantes italianos e seus descendentes instalados no município de Campo Largo (Paraná) no período de 1878 a 1937. Para isso, parte-se do pressuposto de que a identidade de um grupo étnico surge a partir do contato interétnico, ou seja, da necessidade da afirmação de nós diante dos outros. Nessa direção, são analisadas as práticas de transmissão dos nomes de batismo como signo de construção da identidade étnica. Procurou-se verificar como o grupo em estudo construiu sua identidade pautada pelos referenciais simbólicos e culturais da terra de partida e de que forma se dá o processo de mudança tendo em vista a nova realidade e os contatos culturais estabelecidos com os brasileiros. Para conduzir essa análise, utilizaram-se, principalmente, registros paroquiais (atas de batismos, casamentos e óbitos) que foram sistematizados pela metodologia de reconstituição de famílias, oriunda da demografia histórica. Por meio da análise da documentação foi possível perceber nos nomes de batismos a predominância de elementos típicos do mundo rural de origem desses imigrantes que simbolicamente os ligavam à terra de seus ancestrais. Esses elementos foram de grande relevância para a definição da identidade do grupo como ítalo-brasileira.

Palavras-chave: Nomes de batismo. Imigrantes italianos. Campo Largo.

\footnotetext{
*Programa de Pós-Graduação em História da Universidade Federal do Paraná (UFPR), Curitiba-PR, Brasil (fabio_scarpim@ hotmail.com).
} 


\section{Introdução}

Como se escolhe o nome de batismo de uma criança? Atualmente, em nosso mundo globalizado, existe uma infinidade de possibilidades e de fontes de inspiração para a escolha do prenome de um filho. Mas, no passado, como estes eram escolhidos? Nas últimas décadas, os nomes de batismo têm sido objeto de interesse de diferentes pesquisadores (historiadores, sociólogos, antropólogos, linguistas, demógrafos), em função das hipóteses de análise que estes autorizam, como as regras de funcionamento de uma comunidade, as normas de transmissão de bens reais e simbólicos, a ação do Estado e da Igreja, as crenças religiosas, a modernização da sociedade, as relações de gênero e o desenvolvimento do gosto e da moda. Para os propósitos deste artigo, acredita-se que o nome, tanto para quem atribuiu como para quem recebe, é um elemento muito importante na definição da identidade. Conforme Leite de Vasconcellos (apud ROWLAND, 2008, p. 18), em seu estudo clássico Antroponímia portuguesa, "o nome passa a ter simultaneamente uma dimensão social e uma dimensão moral, articulando as identidades pessoais e sociais dos indivíduos e contribuindo, assim, para a constituição social e moral da pessoa”.

Os sujeitos do presente estudo são imigrantes e descendentes de italianos do município de Campo Largo, no Paraná, conformados em uma paróquia entre as décadas finais do século XIX e meados do século XX. O referido município, situado nas proximidades de Curitiba, teve um crescimento populacional significativo com a vinda de centenas de imigrantes europeus nas últimas décadas dos oitocentos, entre eles dezenas de famílias de camponeses vênetos que estavam fugindo do cenário de miséria encontrado nessa região, em função das transformações populacionais, políticas e econômicas. Ao serem instaladas no seu novo ambiente, as famílias imigrantes procuraram se reorganizar na sociedade de adoção como uma comunidade étnica, pautada pelos referenciais socioculturais da terra de origem. Nessa direção, como forma de estabelecer uma ligação afetiva e simbólica com a pátria deixada para trás e diante da situação de estranhamento provocada pelo contato com o outro, esses indivíduos acionaram diversas estratégias de identificação étnica. Vários trabalhos que se ocuparam em analisar a organização de grupos de origem italiana no Brasil salientam a importância que a família e as práticas religiosas tiveram como elementos de etnicidade. Assim, para o grupo em estudo, os nomes de batismo dados às crianças são parte dessas estratégias de reconstrução do mundo simbólico deixado para trás e estão relacionados, principalmente, a esses dois elementos.

A base documental utilizada para analisar as práticas de transmissão de nomes de batismo foi composta basicamente por registros paroquiais (atas de casamento e batismo) e também por registros cartorários de óbitos, que foram sistematizados pela metodologia Fleury-Henry de reconstituição de famílias, oriunda da demografia histórica. Foram levantados 4.337 registros de batismo, 395 de casamento e 467 de óbito, perfazendo um total de 5.199 registros. A documentação arrolada cobre o período de1878 a 1937. A baliza inicial refere-se à criação da primeira colônia italiana no município (Antônio Rebouças), enquanto o marco 
cronológico final está relacionado ao momento em que foi criada oficialmente a Paróquia de São Sebastião, que, por questões de disputas de jurisdição territorial com a paróquia vizinha, perdeu parte significativa de seu território, inclusive muitas famílias de origem italiana. Assim, o recorte espacial cobre basicamente cinco colônias do município de Campo Largo: Antônio Rebouças, Mariana, Campina, Caratuva e Rondinha, sendo esta última o local onde localiza-se a sede da paróquia de São Sebastião.

A documentação paroquial possibilitou fazer uma série de inferências a respeito das práticas de transmissão dos nomes de batismo no interior do grupo étnico. A partir das famílias reconstituídas, procurou-se verificar como o grupo construiu laços de uma sociabilidade característica da sociedade de origem. Observando as famílias reconstituídas, ${ }^{1}$ especialmente aquelas para as quais foram obtidas informações referentes a três gerações, foi possível tabular dados para problematizar a maneira pela qual imigrantes e descendentes atribuíam os nomes de batismo aos seus filhos. A análise da documentação paroquial revelou que as escolhas dos prenomes no interior do grupo não foram aleatórias, muito pelo contrário, estavam influenciadas pela herança cultural trazida da sociedade de origem. Conforme Robert Rowland (2008, p. 18), “independente dos nomes em si, a existência de uma distribuição regular dos nomes próprios em qualquer população, ou a persistência dessa distribuição ao longo do tempo, constitui um indício seguro do caráter socialmente significativo das práticas de nomeação".

\section{As práticas de transmissão de nomes de batismo no grupo italiano}

Os resultados obtidos a partir da sistematização das fontes utilizadas mostraram que a maior parte dos nomes de batismo correspondia aos mesmos dos membros da família ou referia-se aos santos patronos da Igreja. Dessa maneira, é possível afirmar a existência de convenções, ou melhor, "regras" para a escolha dos prenomes entre os imigrantes e seus descendentes. Para os primeiros filhos seriam escolhidos os prenomes dos avós (fossem meninos ou meninas); na sequência seriam escolhidos prenomes de outros parentes (tios, bisavós, irmãos falecidos, entre outros) ou de santos do dia, e para os últimos filhos seriam escolhidos nomes pautados por outros referenciais, como literatura, nomes de personagens históricos ou bíblicos, inventados ou retirados da moda.

O Quadro 1, representado pela prole de um casal, sintetiza o modelo das práticas de nomeação, proposto para o grupo. Esse quadro pode ser considerado um modelo porque caracteriza a sequência mais comum encontrada, em relação às influências presentes na escolha do prenome das crianças numa mesma família. Além disso, é utilizado como referência um casal de descendentes de imigrantes, que nasceram e se casaram em Campo Largo (na colônia Rondinha) e com uma prole numerosa, comportamento característico das famílias

\footnotetext{
${ }^{1}$ Nesse artigo a amostra de famílias reconstituídas que compõem a base de análise de dados corresponde a 265 . Referese a casais que realizaram seu matrimônio entre 1878 e 1920 e que batizaram seus filhos na paróquia entre 1878 e 1937.
} 
em questão. ${ }^{2}$ Nessa direção, parte-se do pressuposto de que a imigração não modificou as práticas de nomeação, pois o grupo continuou, ou mesmo reforçou, os costumes ligados à transmissão dos prenomes que eram praticados na sociedade de origem.

QUADRO 1

Modelo de escolha dos nomes de batismo no grupo italiano. Filhos do casal Antonio e Luigia

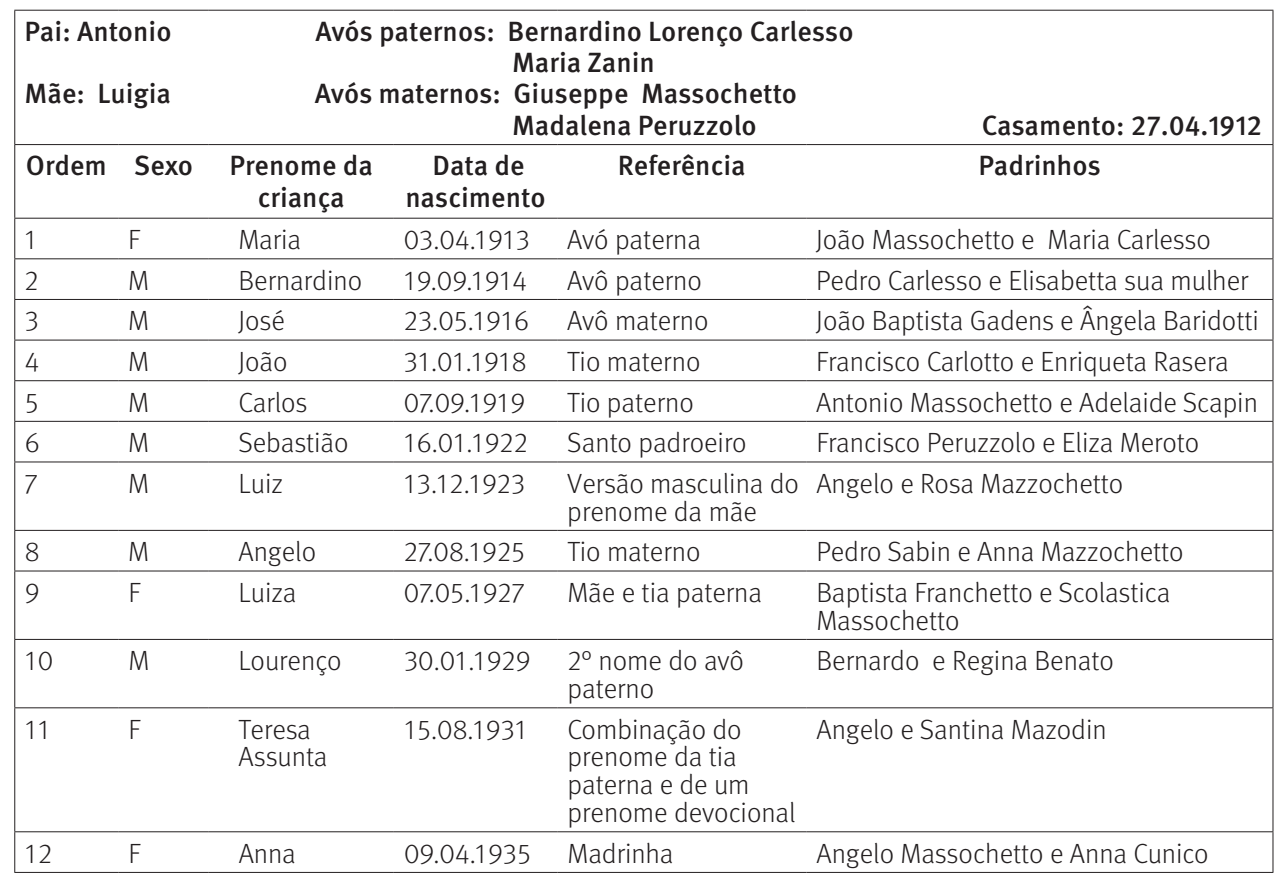

Fonte: Registros de batismo e casamento, acervos da Paróquia de São Sebastião (Campo Largo - PR).

O Quadro 1 mostra que os prenomes, em sua maioria, são os mesmos de membros da família (incluindo o parentesco espiritual). Dos 13 prenomes presentes na prole, 11 expressaram o parentesco. "Receber um nome que faz parte do patrimônio onomástico da família é receber à nascença o símbolo de uma pertença - uma forma de inserção simbólica numa determinada posição hierárquica dentro do grupo familiar" (LIMA, 2007, p. 40). Observase que para a primeira menina foi escolhido o nome de Maria, prenome da avó paterna. 0 segundo filho do casal, como era de costume, recebeu o prenome do avô paterno, assim como o filho da sequência, o do avô materno. Esse exemplo ilustra uma tendência generalizada no grupo em estudo, aquela de privilegiar a via agnática.

Os filhos subsequentes receberam os nomes de outros parentes e nomes devocionais. Para o período em estudo, como as famílias geralmente eram compostas por muitos filhos, entre as convenções para a escolha dos prenomes, era comum que os primeiros honrassem os avós ou pais (fossem meninos ou meninas). Primeiro deveria ser garantida a perpetuação dos nomes dos ancestrais da linha vertical. Para os filhos que nasceriam na sequência, seriam

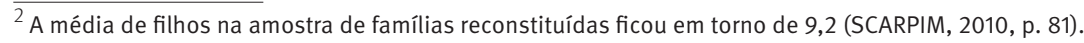


escolhidos os demais parentes (tios, irmãos falecidos, padrinhos), santos do dia, ou outros de preferência do casal (nomes da moda, inspirados em lugares ou coisas, personagens históricos ou bíblicos, ou ainda inventados ou reinventados). Entretanto, esse padrão não era fixo, podendo ser readequado em função de outras motivações ou acontecimentos na vida da família. Exemplo disso, remetendo a outro casal, refere-se ao primeiro filho (Carlo) de Noé Massochetto e Adelaide Scapin, que não recebeu o nome de nenhum parente de sangue, mas sim o do padrinho de batismo do menino, que também fora testemunha do casamento do casal. Nesse caso, parece ter sido mais forte o desejo de homenagear um amigo do que um parente. De maneira similar, o primeiro filho de Luigi Cosmo e Regina Ceccatto foi chamado de Antônio, que também não era prenome de nenhum parente próximo, mas a referência a Santo Antônio de Pádua, já que o menino nasceu no dia do santo (13 de junho).

Sérgio O. Nadalin (2004, p. 5) destaca que os pais, ao escolherem os nomes de seus filhos, são influenciados por uma determinada herança. Assim, é possível acreditar que, quando uma criança nascia e o casal iria escolher o nome, na maioria dos casos o que prevalecia era a força da tradição, do costume. O desejo de manter essa herança cultural está carregado de intencionalidade. A repetição dos nomes próprios dos antepassados também evoca uma memória que se quer preservar. Os laços de identificação simbólica com um passado partilhado pelo grupo têm peso significativo no processo de formação das gerações posteriores, pois são maneiras importantes para se preservarem a coesão familiar e a identidade do grupo (LIMA, 2007, p. 43), além de constituírem uma forma de diferenciação dos outros grupos com que estavam em contato. Nesse sentido, os nomes, assim como a família e a religiosidade, também se manifestam como estratégias de identidade.

Para Denys Cuche (1996), a estratégia de identidade pressupõe consciência. Entretanto, o indivíduo como ator social não é desprovido de uma certa margem de manobra. Em função de sua avaliação da situação, ele utiliza seus recursos de identidade de maneira estratégica. Nessa direção, os atores sociais não são totalmente livres para definir sua identidade segundo interesses materiais e simbólicos. As estratégias devem levar em conta a situação social e as relações de força de cada momento (CUCHE, 1996, p. 196-197). Já para Bourdieu (1987, p. 198), “o caráter estratégico da identidade não implica necessariamente em uma perfeita consciência dos objetivos buscados pelos indivíduos e tem a vantagem de dar conta dos fenômenos de eclipse ou de despertar de identidade”. Dessa maneira, as práticas nomeativas não são simplesmente formas de homenagear indivíduos, mas sim de afirmar a identidade com o grupo (WOORTMANN, 1996, p. 210).

A Tabela 1 mostra como estão distribuídas as influências na escolha dos nomes de batismo. ${ }^{3}$ Embora exista uma distribuição regular de meninos e meninas batizados com os

\footnotetext{
$\overline{3}$ A tabela foi dividida em categorias conforme as influências encontradas na documentação paroquial (pais, avós, tios, padrinhos, irmãos falecidos, santo do dia, outros parentes e outros) e também em coortes, que levam em consideração os casais que realizaram matrimônio naquele espaço de tempo e cuja descendência é seguida nos registros de batismo ao longo do período estudado. As coortes foram organizadas em períodos médios de uma década, com exceção da primeira, que incorpora um recorte temporal maior, pois as famílias vão se estabelecendo nas colônias ao longo dessa coorte. Foi procedida dessa maneira, para equiparar o número de famílias por coorte.
} 
prenomes dos avós paternos e maternos, algumas diferenças podem ser notadas. Para os meninos, com exceção da primeira coorte, evidencia-se a maior influência do avô paterno. Apesar de prevalecer um equilíbrio entre as linhagens, a via masculina foi privilegiada, sendo que, geralmente, o primogênito recebia o prenome do avô paterno. A ideia de garantir a perpetuação da linhagem por meio do nome fazia com que o lado do pai fosse o primeiro a ser lembrado. Assim, este costume poderia estar ligado ao próprio modelo de sociedade que o grupo estava reconstruindo. Se um casal viesse a ter um único filho homem, este deveria portar um prenome herdado do lado do chefe da casa. Já para as meninas a preferência recaía sobre o lado da mãe, pois, com exceção da segunda coorte, a avó materna é mais requisitada que a paterna. Privilegiar a escolha do prenome do avô paterno para os meninos e o da avó materna para as meninas parece constituir um padrão clássico de transmissão dos nomes de batismo, encontrado em diversas regiões da Europa (SANGOÏ, 1999, 2008; BURGUIÈRE, 1980; ZONABEND, 1980, entre outros).

TABELA 1

Crianças nascidas nas famílias reconstituídas, por influência nas escolhas dos prenomes de batismo, segundo período do casamento

Colônias italianas de Campo Largo (PR) - 1878-1920

\begin{tabular}{|c|c|c|c|c|c|c|c|c|c|c|c|c|}
\hline \multirow[t]{2}{*}{ Coorte } & \multirow[t]{2}{*}{$\begin{array}{l}\mathrm{N}^{\circ} \text { de } \\
\text { casais }\end{array}$} & \multirow[t]{2}{*}{$\begin{array}{l}\text { Sexo da } \\
\text { criança }\end{array}$} & \multicolumn{4}{|c|}{ Influência paterna } & \multicolumn{4}{|c|}{ Influência materna } & \multicolumn{2}{|c|}{$\begin{array}{l}\text { Influência } \\
\text { dos irmãos } \\
\text { falecidos }\end{array}$} \\
\hline & & & Pai & Avô & Avó & Tio (a) & Mãe & Avô & Avó & Tio (a) & Irmão & Irmã \\
\hline \multirow{2}{*}{$1878-1900$} & \multirow{2}{*}{83} & Menino & 16 & 50 & 4 & 28 & 1 & 56 & - & 60 & 20 & - \\
\hline & & Menina & 2 & - & 40 & 27 & 5 & 2 & 52 & 45 & - & 8 \\
\hline \multirow{2}{*}{ 1901-1910 } & \multirow{2}{*}{95} & Menino & 18 & 79 & 5 & 32 & 2 & 64 & 3 & 13 & 14 & - \\
\hline & & Menina & 8 & 4 & 68 & 34 & 11 & 7 & 64 & 35 & - & 10 \\
\hline \multirow{2}{*}{ 1911-1920 } & \multirow{2}{*}{87} & Menino & 5 & 52 & 1 & 22 & 1 & 40 & 2 & 7 & 6 & - \\
\hline & & Menina & 1 & 1 & 35 & 15 & 7 & 3 & 38 & 18 & - & 9 \\
\hline \multirow{2}{*}{ 1878-1920 } & \multirow{2}{*}{265} & Menino & 39 & 181 & 10 & 82 & 4 & 160 & 5 & 80 & 40 & - \\
\hline & & Menina & 11 & 5 & 143 & 76 & 23 & 13 & 154 & 98 & - & 27 \\
\hline \multirow[t]{2}{*}{ Coorte } & \multirow{2}{*}{$\begin{array}{l}\mathrm{N}^{\circ} \text { de } \\
\text { casais }\end{array}$} & \multirow{2}{*}{$\begin{array}{l}\text { Sexo da } \\
\text { criança }\end{array}$} & \multicolumn{4}{|c|}{$\begin{array}{c}\text { Influência dos } \\
\text { compadres }\end{array}$} & \multirow{2}{*}{$\begin{array}{l}\text { Santo } \\
\text { do dia }\end{array}$} & \multirow{2}{*}{\multicolumn{2}{|c|}{$\begin{array}{l}\text { Outro } \\
\text { parente }\end{array}$}} & \multirow[t]{2}{*}{ Bisavô } & \multirow[t]{2}{*}{ Outros } & \multirow[t]{2}{*}{ Total } \\
\hline & & & Padri & nho & Madrin & nha & & & & & & \\
\hline \multirow{2}{*}{ 1878-1900 } & \multirow{3}{*}{83} & Menino & & 28 & & - & 19 & & 26 & 20 & 60 & 348 \\
\hline & & Menina & & - & & 22 & 4 & & 27 & 12 & 77 & 306 \\
\hline \multirow{2}{*}{ 1901-1910 } & & Menino & & 23 & & - & 23 & & 14 & 11 & 54 & 354 \\
\hline & 95 & Menina & & - & & 20 & 5 & & 23 & 3 & 100 & 382 \\
\hline \multirow{2}{*}{$1911-1920$} & \multirow{3}{*}{87} & Menino & & 5 & & - & 10 & & 19 & 3 & 68 & 241 \\
\hline & & Menina & & - & & 8 & 4 & & 13 & 1 & 79 & 232 \\
\hline \multirow{2}{*}{ 1878-1920 } & & Menino & & 56 & & - & 52 & & 59 & 34 & 182 & 943 \\
\hline & 265 & Menina & & - & & 50 & 13 & & 63 & 16 & 256 & 920 \\
\hline
\end{tabular}

Fonte: Registros de Batismo e Casamento, Acervos da Paróquia de São Sebastião (Campo Largo - PR).

O costume de transmitir os nomes dos avós se manteve latente em boa parte da Europa até o século XIX. Essa prática está diretamente ligada à ideia de que o nome é um patrimônio 
simbólico familiar, assim como à necessidade de marcar a posição do indivíduo no interior da linhagem. Entretanto, a crença na reencarnação parece ser um componente peculiar na explicação dessa prática. Nas sociedades camponesas a concepção de mundo estava estreitamente ligada a terra.

Cada indivíduo descrevia um arco de vida, mais ou menos longo, segundo a duração de sua existência: saía da terra através da concepção e a ela voltava através da morte. Sob a terra estava a morada dos mortos, a reserva da alma à espera de uma reencarnação, essas almas dos ancestrais que 'renderam o espírito' e um dia renasceriam num de seus netos. Aliás, não perdurou por muito tempo o hábito de dar às crianças o nome dos avós como que para melhor assegurar a continuidade da família? (GÉLIS, 1999, p. 311)

Até o início da grande emigração (1850-1939), a maior parte da Europa ainda era predominantemente agrária. Na Itália, a expectativa de vida era relativamente baixa. Assim, muitas vezes, o momento de morte dos avós coincidia com o nascimento dos netos. Aliás, muitos avós nem chegavam a conhecer seus netos. Esse modo de viver extremamente instável, que oscilava entre a vida e a morte, teria contribuído para a manutenção dessas crenças, ligadas ao próprio ciclo da natureza? No mundo rural, embora a crença na reencarnação tenha sofrido um desgaste ao longo do tempo, o costume de dar às crianças o nome dos avós permaneceu bastante forte e se tornou uma tradição que só iria decair no século XX (POPPEL et al., 1999).

A escolha dos nomes dos membros do grupo familiar, especialmente dos ancestrais, é um componente que explica a importância da linhagem e da organização da família no mundo camponês. Segundo Françoise Zonabend (1980), o nome constitui um meio de guardar uma relação comum entre os membros dispersos de uma parentela. Ao se perpetuar de geração em geração no interior da mesma linhagem, determinado prenome se transforma em um emblema de pertencimento, um brasão de reconhecimento.

Além dos tios, avós e pais, influências de outros parentes (incluindo o parentesco espiritual) também estiveram presentes na escolha dos nomes de batismo do grupo em estudo. Seguindo o modelo proposto para as práticas de nomeação, após reverenciar os avós, para os últimos filhos seriam escolhidos prenomes dos tios, dos santos, da moda, mas também dos padrinhos e outros parentes. O parentesco espiritual, muitas vezes, tinha por função estreitar laços entre famílias. Nesse sentido, a escolha do mesmo nome do padrinho ou madrinha da criança reforçaria essa ideia. Pitt Rivers, ao investigar sobre as funções práticas e ideológicas do compadrio no sul da Espanha, enfatiza a conexão entre a instituição e o nome dado à criança. Segundo o autor, o ritual de aquisição do nome cristão marca o início da personalidade social do indivíduo e, sendo este herdado do padrinho ou madrinha, é com ele que haveria uma maior identificação (RIVERS apud BLOCH; GUGGENHEIM, 1981, p. 378). Sendo o batismo um segundo nascimento, o qual necessitava de novos pais, o ato de dar o nome do padrinho seria uma forma de concretizar a paternidade espiritual (BURGUIÉRE, 1980, p. 31). Como sabemos, o compadrio traduz significados simbólicos, entretanto, além destes, o ritual do batismo tem um significado muito concreto: a segurança não só material, 
mas também afetiva da criança, pois os pais esperam que os compadres eleitos sejam pais substitutos de seus filhos, no caso de uma infelicidade (NADALIN, 1996, p. 1.650).

Entre os italianos, os pais espirituais geralmente eram escolhidos entre os parentes, vizinhos ou amigos. Diferente de outras regiões da Europa como a França, a escolha dos avôs para apadrinhar um neto não foi tão comum, sendo que a maior parte dos padrinhos correspondia a pessoas da mesma faixa etária dos pais. Por meio dos dados da Tabela 1 observa-se que o compadrio, com exceção da primeira coorte, não exerceu grande influência nos nomes das crianças. Aliás, uma questão permanece em aberto: o declínio do uso dos prenomes dos padrinhos seria um indício do desgaste desse costume iniciado na Itália antes de os imigrantes partirem, ou seria mesmo um hábito pouco praticado na sociedade de origem? Talvez o próprio fato de serem os pais os responsáveis pela escolha do prenome da criança contribuiu para a baixa influência dos padrinhos. Uma questão difícil de ser respondida é se os padrinhos que tiveram os nomes dados aos seus afilhados foram escolhidos por causa dos nomes que seriam transmitidos às crianças, uma vez que a análise de algumas famílias mostrou que, para a escolha dos pais espirituais, não havia "regras" estritas como para os nomes.

A menor influência dos padrinhos talvez possa ser explicada pelo próprio fato de estes geralmente serem da mesma faixa etária dos pais, enquanto a tradição da escolha dos nomes recaía sobre aqueles de pessoas mais velhas ou falecidas. Evidencia-se uma estratégia interessante: a escolha dos nomes reforçava o vínculo com a sociedade de origem, enquanto o compadrio cimentava relações de solidariedade e amizade entre os familiares, amigos e vizinhos da sociedade de adoção.

Entre os alemães de Dois Irmãos (RS), a antropóloga Ellen Woortmann (1995) constatou que uma das características do padrão de compadrio é a alternância de gerações, ou seja, o afilhado de um padrinho será o padrinho do neto de seu próprio padrinho. Em muitos casos o apadrinhamento de uma criança vinha acompanhado do nome também. Nesse sentido, fazendo uso do conceito maussiano de dádiva, temos nessa relação uma troca enquanto um “reforço de realidades pré-existentes" (MAUSS, 1986, p. 41). Por outro lado, esse padrão de reciprocidade apoiava-se, também, na ideia de que o afilhado era devedor do padrinho e que a dívida era paga assumindo, para com o neto deste, a mesma obrigação (WOORTMANN, 1995, p. 201). A relação entre a aquisição do nome e o vínculo de compadrio poderia ser uma forma de cimentar relações de parentesco na sociedade de adoção, ou por meio de uma ligação afetiva e simbólica com a terra de origem.

O vínculo estabelecido com as gerações ancestrais por meio do nome fica evidente em alguns casais que nomearam seus filhos, especialmente o primeiro, não com o nome dos avós, mas sim dos bisavós. Os dados da Tabela 1 evidenciam que, na primeira coorte, essa opção foi significativa principalmente para os meninos. Na verdade, esses números são parciais, uma vez que somente em parte dos casos foi possível recuperar os prenomes dos bisavós. A maior parcela dos dados refere-se a uma colônia específica (Campina) e foi obtida por meio da genealogia das famílias pioneiras. É provável que a opção pela escolha dos prenomes dos bisavós, em algumas ocasiões, reflita o costume de dar o nome 
de um falecido à criança, uma vez que, na maioria dos batismos, o bisavô já estava morto e enterrado na Itália. Exemplo disso foram os dois primeiros filhos (Luigi e Giuseppe) de Fioravante Camillo e Antonia Maria Simonetto, que receberam os nomes dos dois bisavós paternos.

Além dos bisavós, nomes de outros parentes (vivos ou mortos) também foram escolhidos. Como foi encontrada uma variedade de influências (primos, esposa ou marido falecido(a) do casamento anterior, ou com outro grau de parentesco que não foi possível definir), todas essas referências foram incluídas em uma só categoria. Em alguns casos os prenomes poderiam ser escolhidos pelo apreço do casal por aquele nome, para combinar com outro prenome de família, pela trajetória de vida daquele indivíduo (no caso de falecido), ou até mesmo para estreitar um laço de amizade com aquela pessoa. Assim como os bisavós, nomes de pessoas falecidas também eram escolhidos. Em 28 de agosto de 1885 selaram a união matrimonial dois viúvos: Alessio de Tomasi e Antonia Filipetto Fabris. O primeiro filho do casal, uma menina, recebeu o nome da esposa falecida do noivo (Cattarina). Da mesma maneira, a primeira filha de João Toresin e Angela Cequinelli recebeu o nome de Anneta, provavelmente uma forma carinhosa de homenagear Anna, a esposa morta de João.

Ao longo do processo de reconstituição das famílias, um fato recorrente chamou atenção: muitos casais tinham dois filhos que portavam o mesmo prenome. A suspeita inicial, que se concretizaria nas evidências posteriormente encontradas, é que estes nomes referiam-se a crianças falecidas. Como na paróquia não havia o livro de óbitos, tornou-se necessário recorrer a outras fontes, como os registros cartorários e os registros da Caixa Mortuária. Entretanto, as fontes referentes aos falecimentos mostraram-se fragmentárias e lacunares. De qualquer forma, foi possivel recuperar parte das informações sobre os óbitos de crianças.

A prática de dar o mesmo nome do irmão falecido ao filho subsequente mostrou-se significativa. A maioria dos casais que tinham um filho falecido o homenageava colocando seu nome em um irmão que nascesse depois. É claro que esses dados não correspondem ao total de crianças com nome dos irmãos falecidos, mas sim a uma amostra. Numerosos estudos mostram que, particularmente nas regiões mediterrânicas da Europa, dar o prenome de um parente falecido para a criança era uma obrigação explícita (SANGOÏ, 1999).

Na concepção de mundo camponesa, a ideia do ciclo da vida associado à terra parece ter uma estreita relação com essa prática. Somado a essas crenças, dar o mesmo prenome do irmão falecido teria a finalidade de "refazer" o indivíduo no interior da linhagem, ao colocar o mesmo nome em um novo nascimento. Esse costume coloca em evidência a concepção de comunidade, típica do mundo camponês, que não abrangia somente os vivos, mas também os mortos. Basta lembrar que na Itália, até pelo menos o final do século XIX, a morte de crianças prematuramente ainda era fato corriqueiro. Portanto, a convivência com a morte fazia parte do cotidiano do mundo camponês.

Os nomes dos falecidos também podem evidenciar a crença na reencarnação, oriunda dos cultos agrários, que, embora refutada pela Igreja, se manteve presente no mundo rural. 
A tradição do culto aos mortos foi uma das práticas fundamentais de quase todas as religiões, mesmo as mais primitivas. Inicialmente, o culto aos mortos esteve ligado aos cultos agrários e aos da fertilidade da terra. 0 defunto como as sementes, eram enterrados com vista a uma futura ressurreição ou nascimento. Como as sementes, esperavam a volta a uma nova vida. Por isso, a ideia central da festa dos mortos é a mesma dos ritos agrários e da fecundidade: retorno a vida que deve surgir de algo oculto e misterioso, da morte, como a planta surge das sementes inertes (FOCHESSATO, 1980, p. 11).

Por outro lado, na liturgia cristã, o nascimento espiritual de uma criança que recebe juntamente com a água do batismo seu nome anularia a morte do portador de seu prenome que a precedeu (KLAPISCH-ZUBER, 1980, p. 100). Ao utilizar o mesmo nome, a criança falecida teria um representante legítimo na terra capaz de assegurar seu descanso no mundo dos mortos e de zelar pelo seu espírito. Assim,

na cultura cristã, o nome de batismo tinha uma dupla função propiciatória. Aquela de assegurar à criança a saúde e a felicidade no mundo, mas também uma boa morte e a vida eterna: era o nome de batismo inscrito no "livro da vida" que se encontrava no céu, e era a maneira como poderia ser reconhecido, quando evocado nas orações (FINE apud NADALIN, 2004, p. 5).

Dar aos novos nascimentos o nome dos mortos também seria uma maneira de os vivos interceder, com suas rezas e orações, na salvação de suas almas. No mundo colonial italiano, o culto aos mortos era uma forma de afirmação da vida para além da morte. Eles entendiam que os falecidos estavam, de certo modo, unidos aos seus familiares e, por isso, eram muito lembrados nas orações, missas e também nos nomes (FOCHESSATO, 1978, p. 27).

A perpetuação dos prenomes dos falecidos também pode estar associada a devoções e funções denotativas do poder simbólico do nome. Baptista Cavallin e Maria Alessi tiveram 12 filhos. O sexto filho do casal foi batizado como Antonio, uma provável referência ao santo, já que nasceu em 14 de junho. 0 menino veio a falecer e o filho subsequente recebeu o nome do irmão falecido, mas esse também faleceu e o último filho do casal foi novamente nominado de Antonio. O que teria feito o casal não desistir do nome, mesmo depois de duas mortes? Seria a crença no poder do prenome, que era o mesmo do santo? Uma promessa? A força da tradição? O desejo de perpetuar esse prenome? Na verdade poderia ser qualquer uma das opções, ou mesmo todas juntas. Em algumas famílias, a prática de transmitir os mesmos nomes dos irmãos foi rigidamente seguida. Olivo Bertoja e Dominga Cunico tiveram 15 filhos, sendo que quatro morreram e todas essas crianças tiveram seus nomes lembrados nos filhos que nasceram na sequência.

Além dos nomes retirados da família, nas práticas de nomeação a religião também tem papel significativo. Entre as populações católicas da Europa, os nomes dos santos, desde muitos séculos, têm sido uma fonte inspiradora para a escolha do nome de batismo. Os nomes retirados do calendário litúrgico, ou escolhidos por outro motivo religioso, podem ser resultado de devoções pessoais, ou mesmo estarem relacionados às influências da Igreja. Entre os italianos, a autoridade do padre também poderia influenciar os pais da criança a ser batizada, na escolha do nome. No grupo em estudo, muitos nomes referiam-se aos patronos da Igreja, mas nem todos foram escolhidos em função deles. Provavelmente, a 
difusão desses prenomes remonte a própria influência da Igreja Católica na cristianização dos nomes próprios, processo que se intensificou no período pós-reformas religiosas do século XVI.

O Concílio de Trento prescrevia que a criança deveria receber um nome de batismo cristão, um nome piedoso que evocasse as virtudes do seu portador, assim como seria um símbolo de fidelidade a Deus (DUPÂQUIER, 1980, p. 5). Para a Igreja, o prenome tinha um valor pedagógico: a criança tinha que imitar as qualidades de seu patrono (SANGOÏ, 1999, p. 5). Na verdade, a tentativa de impor a supremacia dos nomes cristãos vem desde pelo menos o século XII, mas esse processo só intensificou-se a partir do século XVI. Especialmente nas áreas pouco atingidas pelo protestantismo, como a França, a Itália e a Península Ibérica que se mantiveram fortemente fiéis ao catolicismo, o uso dos nomes dos santos se deu de maneira intensa.

A utilização de certos prenomes por determinada família também serve para o estudo das devoções particulares. No grupo analisado, a prática relacionada ao uso de nomes de santos podia ser o resultado da afirmação de devoções familiares, de promessas realizadas ou até mesmo da influência do padre. Os nomes devocionais podiam ser o resultado de uma troca, ou, no sentido maussiano, uma dádiva (MAUSS, 1974), uma forma de estabelecer um contrato com o sagrado: o nome do santo em troca de suas bênçãos, ou de sua proteção para o indivíduo durante toda sua vida.

Além da relação com o calendário litúrgico, muitos dos padroeiros das colônias tinham seus nomes dados a muitas crianças. Na verdade, a escolha de determinado santo como padroeiro reflete as próprias devoções das aldeias de origem de muitas famílias de imigrantes. Nossa Senhora do Carmo é padroeira da colônia Antonio Rebouças e é justamente nessa região que foi batizada a maior parte das meninas com os nomes Carmem, Carmella, Carmelita e Carmelina. No núcleo colonial de Mariana, que tem como padroeira Nossa Senhora da Anunciação, também está concentrada a maior parte das meninas nomeadas como Núncia ou Anunziata. Já para os meninos, foram encontradas muitas crianças batizadas de João Batista, em Campina, que tem este santo como patrono, assim como a maioria com o nome Sebastião nasceu na colônia sede da paróquia (Rondinha), que tem como padroeiro São Sebastião.

Os prenomes retirados de determinado estoque familiar, ou do calendário litúrgico, constituem a maior parte do rol daqueles utilizados. Entretanto, apesar de esporádicos, alguns nomes bastante inusitados chamam a atenção. O uso de Itália ou Ítalo como nome de batismo parece não ter sido fato incomum nos diversos núcleos coloniais do Sul do Brasil. Conforme cita o padre Henrique Vieter, em Silveira Martins, no Rio Grande Sul, foram constantes as lutas dos sacerdotes palotinos para a “cristianização” de alguns nomes próprios demasiadamente ligados ao nacionalismo italiano.

Os italianos muitas vezes davam o nome de Ítalo aos meninos, e Itália às meninas, e contra isso nada se podia fazer. Para evitar longas discussões eu lhes dizia: 'tomemos São José por protetor', e batizava o menino com o nome de José Ítalo. As meninas também merecem uma grande padroeira, e thes dava o nome de Maria Itália, com o que os colonos se sentiam muito satisfeitos (VIETER apud POSSAMAI, 2005, p. 147). 
Embora, dentro do grupo em questão, fossem poucas as meninas batizadas como Itália, tanto de forma simples como combinada, o caso de uma família específica merece ser destacado. O segundo e terceiro filhos do casal Domingo Bianco e Maria Vechiato, um menino e uma menina, receberam os prenomes de Vitório e Itália, respectivamente. Esses prenomes parecem não ser herdados de nenhum parente próximo, mas provavelmente referências ao país de origem de seus pais. Vitório poderia ser uma referência ao primeiro nome do rei italiano (Vittore Emanuelle) e o da menina, a menção à própria pátria de origem.

A análise das famílias reconstituídas mostrou a influência de diferentes elementos nas escolhas dos prenomes (bisavós, avós, tios, padrinhos, irmãos falecidos, santos do dia). Entretanto, em uma parte dos prenomes dados às crianças, na amostra de famílias utilizada, não foi possível identificar uma provável razão para tal escolha. Todos esses casos de origem indeterminada foram inseridos na categoria "outras influências". Os dados apresentados na Tabela 1 evidenciam duas características. Primeiro em relação à diferença de gênero. Como nas demais categorias, percebe-se que as “regras" sempre são mais rígidas para os meninos do que para as meninas. Seria uma valorização maior do gênero masculino, característica das sociedades patriarcais, que se expressava também nas práticas de nomeação? Provavelmente, foi sobre as mulheres que o uso de prenomes retirados da moda, de personagens da literatura, ou mesmo inventados se manifestou primeiro. Assim, sendo a pressão social menos forte sobre as meninas, prenomes "novos" seriam primordialmente utilizados para elas (NADALIN, 2007b, p. 28). Na cultura do mundo camponês tradicional, predominavam a hegemonia simbólica masculina e a subordinação feminina (LIMA, 2007, p. 52). Nas sociedades ditas tradicionais, as regras de transmissão do patrimônio simbólico seguem as mesmas do patrimônio material. Como em geral, eram os homens os herdeiros das possessões materiais da família e era sobre estes que a atribuição dos prenomes deveria se manter mais rígida.

A escolha de um nome também poderia estar associada a um significado conotativo. Segundo a definição de Sonderegger (apud SIEMENS, 1992, p. 34), o significado conotativo é a soma das associações, imagens e sentimentos ligados a ele, quer sejam positivos, quer neutros, quer negativos. Essa conotação pode ser evocada pelo corpo sonoro, pela forma escrita do nome, pelo portador, pela capacidade de imaginação do ouvinte, ou, até mesmo, pelo seu significado etimológico, na medida em que for possível identificá-lo. Entre os descendentes de italianos do grupo em estudo, era comum a modificação de determinados prenomes a partir do nome de batismo de um familiar. Nessa direção, principalmente para o gênero feminino, existem muitos prenomes terminados em -ina, como: Paolina (de Paola), Orsolina (de Orsola), Carmelina (de Carmela), Pasqualina (de Pasqua), Angelina (de Angela), Rosalina (de Rosa), Santina (de Santa). O objetivo dessa prática parece ter uma dupla função: ao mesmo tempo que se buscava a inovação, a escolha de um prenome pouco comum e assim sublinhar a identidade do indivíduo, homenageava-se um membro da família. Era escolhido um nome diferente, mas que não deixava de evocar um parente. Dito de outra forma, a própria repetição gerava essas “corruptelas”, tendo em vista a conciliação entre a tradição e a criação de uma nova identidade para a criança por meio do nome. Por outro 
lado, essas modificações de prenomes, especialmente femininos, evidenciam as diferenças nas formas de nomear homens e mulheres naquela sociedade. ${ }^{4}$

Além da diferença de gênero, percebe-se que para a última coorte, em relação às demais, há um aumento de nomes escolhidos a partir de outros referenciais. Seria resultado do próprio tamanho das famílias? Como eram muitos os filhos, escolhiam-se os prenomes dos antepassados para os primeiros, enquanto para os demais seriam buscados outros prenomes, abrindo espaço, inclusive, para a inovação, a moda, ou mesmo nomes de uso corrente na sociedade receptora, evidenciando assim um estreitamento dos contatos culturais e a diluição da fronteira etnocultural. O casal João Massochetto e Catterina Gadens, casados em 05 de julho de 1913, escolheu para os primeiros filhos os nomes dos avós, enquanto para os dois nascimentos seguintes foram escolhidos prenomes pautados por outros referenciais (Desidério e Orlindo). Da mesma forma, Angelo Micheletto e Maria Costa, casados em 31 de julho de 1915, para as primeiras filhas escolheram os prenomes das duas avós e, para as demais meninas (Agnes, Narcisa, Emma e Doralise), atribuíram nomes de pouco uso no grupo. Seria uma forma de individualizar as crianças com um nome pouco utilizado, uma vez que várias outras meninas da região onde o casal morava portavam "nomes tradicionais". Por outro lado, poderia ser referência a um parente distante ou mesmo a uma amiga, o que não foi possível evidenciar na documentação.

Alguns casos "saltam aos olhos" pelo seu caráter inusitado. José Peruzzolo e Antonia Bisetto, casados em 25 de maio de 1918, batizaram nove filhos na paróquia e para todos eles (Idalina, Abílio, Mercede, Oreste, Maria Genaide, Lídia, Amadeo, Rodolpho e Lauro) não foi possível relacionar a nenhuma das categorias anteriormente mencionadas. Entretanto, se alguns prenomes foram buscados na moda ou em um referencial distante que não foi possivel localizar neste estudo, muitos deles, independentemente da influência, passaram a fazer parte do estoque onomástico da família. Em 1921, o oitavo filho de Vitório Scapin e Maria Zanin e o sétimo filho de Noé Mazzuchetto e Adelaide Scapin foram batizados como Zepherino. Independentemente do motivo pelo qual o primeiro menino foi assim nomeado, acabou por influenciar o nome do primo que nasceu naquele mesmo ano. Dois outros casos são interessantes para serem destacados, porque, mesmo não sendo prenomes de um parente próximo, estes são reafirmados na prole do casal.

O costume de se atribuírem prenomes pautados por outros referenciais mostrou-se significativo, especialmente, para os últimos filhos do casal. Na maior parte dos casos, para os primeiros filhos (sejam meninos ou meninas) eram escolhidos os prenomes dos avós, ou outro parente, enquanto para os últimos os pais estariam mais livres para escolher outros prenomes, que poderiam ser retirados de membros mais distantes da família, nomes devocionais, de personagens históricos, de pessoas importantes ou mesmo da moda. Após terem referenciados seus diversos parentes (vivos ou mortos) para os primeiros filhos, à

\footnotetext{
$\overline{{ }^{4} \text { Sérgio Odilon Nadalin }}$ (2004, 2007a, 2007b), em seus estudos sobre os alemães luteranos em Curitiba, constata que até cerca de 1920 são os prenomes femininos que lideram o alargamento do estoque onomástico, enquanto nas duas décadas seguintes há uma inversão, ficando os prenomes femininos mais próximos das tradições alemãs.
} 
medida que iria se caminhando para o final da prole, as "regras" estariam mais flexíveis, possibilitando aos pais escolher outros prenomes, podendo, inclusive, inovar. Atitudes como essas podem ser indicativos de que a "fronteira etnocultural" estava sendo deslocada. Segundo Barth (1998, p. 201), as fronteiras não são imutáveis, mas sim concebidas como uma demarcação social suscetível de ser constantemente renovada pelas trocas.

\section{Considerações finais}

O fenômeno da imigração certamente trouxe uma grande mudança para todos os grupos que deixaram definitivamente sua terra natal. Entretanto, o ato de emigrar não implicou, necessariamente, uma ruptura completa das estruturas socioculturais e simbólicas da terra de partida. Muito pelo contrário, as atitudes dos diversos grupos étnicos foram no sentido de reconstruir a vida na nova pátria com base nos elementos da sociedade original. Assim, todo um arcabouço cultural e simbólico foi transportado e reelaborado nesse processo. Tais atitudes puderam ser percebidas nas práticas de transmissão dos nomes de batismo, em que ficou clara a presença de crenças, costumes, imaginários e tradições típicas do mundo rural italiano. Seja como uma marca social, religiosa ou familiar, o nome de batismo é uma referência identitária. Mais que o estudo de tradições, a análise dos nomes de batismo revelou-se como uma outra referência de etnicidade (NADALIN, 2007a, p. 16). A família e a religiosidade foram signos importantes demarcadores da identidade e, assim, constituíram praticamente a base de orientação para a escolha dos nomes entre os imigrantes e descendentes. Por mais que o grupo italiano tenha cortado muitos laços que uniam-no à "sociedade emissora", continuou a manter ligações afetivas e simbólicas. Percebendo a diferença com os outros grupos que estavam em contato, esses italianos e seus descendentes passaram a reavaliar a orientação de seus valores fundamentais e os sinais ou signos por meio dos quais se identificavam (NADALIN, 2007a, p. 18). Assim, a forma pela qual o grupo fazia a transmissão dos prenomes tem caráter muito relevante para a análise de como se deu o processo de construção da identidade coletiva.

\section{Referências}

BARTH, F. Grupos étnicos e suas fronteiras. In. POUTIGNAT, P.; STREIFF-FENART, J. Teorias da etnicidade. São Paulo: Unesp, 1997.

BLOCH, M.; GUGGENHEIM, S. Compadrazgo, baptism and the simbolism of a second birth. Man, New series, v. 16, n. 3, p. 376-386, Sep. 1981. Disponível em: 〈www.jstor.org/stable/2801290〉.

BORDIEU, P. A economia das trocas simbólicas. São Paulo: Perspectiva, 1987.

BURGUIÉRE, A. Prénoms et parenté. Lê prénom, mode et Histoire. Les Entretiens de Malher. Paris: Édition de L'École des Hautes Etudes em Sciences Sociales, 1980.

DUPÂQUIER, J. Introduction. Lê prénom, mode et Histoire. Les Entretiens de Malher. Paris: Édition de L'École des Hautes Etudes em Sciences Sociales, 1980.

FOCHESSATO, I. Descrição do culto aos mortos entre os descendentes de italianos do Rio Grande do Sul. Caxias do Sul: EST, 1977.

GÉLIS, J. A individualização da criança In: ÀRIĖS, P. (Org.). História da vida privada 3. Da Renascença 
ao século das luzes. São Paulo: Cia das Letras, 1997.

HENRY, L. Téchniques d'analyse en démographie historique. Paris: INED, 1980.

KLAPISCH-ZUBER, C. Constitution et variations temporelles des stocks de prénoms. Lê prénom, mode et Histoire. Les Entretiens de Malher. Paris: Édition de L'École des Hautes Etudes em Sciences Sociales, 1980.

LIVROS de batismo e casamento das Paróquias de São Sebastião (Campo Largo- PR), № Sra da Piedade (Campo Largo-PR) e São José (Santa Felicidade - Curitiba).

LIVROS de óbito do Cartório de Registros Civis de Campo Largo-PR (Cartório Leandro).

LIMA, A. P. de. Intencionalidade, afecto e distinção: as escolhas de nomes em famílias de elite de Lisboa. In: CABRAL, J.; VIEGAS, S. de M. (Orgs.). Nomes: gênero, etnicidade e família. Coimbra: Almedina, 2007. MAUSS, M. O ensaio sobre a dádiva. Sociologia e Antropologia. São Paulo: Pioneira/Edusp, 1974.

MERCER, J. L. da V.; NADALIN, S. O. Um patrimônio étnico: os prenomes de batismo. Topoi, v. 9, n. 17, p. 12-21, jul.-dez. 2008.

NADALIN, S. O. O compadrio batismal a partir dos registros paroquiais: sugestões metodológicas II. In: X ENCONTRO NACIONAL DE ESTUDOS POPULACIONAIS. Anais... Abep, v. 3, 1996. Disponível em: $\langle$ 〈www.abep.nepo.unicamp.com.br〉

Construção e "desconstrução" de uma cultura imigrante: atribuição de nomes de batismo, parentesco e compadrio. Séculos XIX e XX. CNPQ Processo 301564/2007-8, 2004 (Projeto de pesquisa).

. João, Hans, Johan, Johannes: dialética dos nomes de batismo numa comunidade imigrante.

Revista História Unisinos, v. 11, n. 1, jan./abr. 2007 a.

Um viés determinado pela etnicidade: os nomes de batismo - Registros paroquiais de uma comunidade luterana, séculos XIX e XX. Campinas: Nepo/Unicamp, 2007b.

POPPEL, F. V.; BLOOTHOOF, T. G.; GERRITZEN, D.; VERDUIN, J. Naming for kin and the development of modern family structures: an analysis of a rural region in the Netherlands in the nineteenth and early twentiefh centuries. The history of the family, n. 4, p.261-265, 1999. Disponivel em: «www.let.uu.nl. gerrit.blooth/personal/HISTFAM.1999.html/>. Acesso em: 15 maio 2008.

ROWLAND, R. Práticas de nomeação em Portugal durante a Época Moderna: ensaio de aproximação. Etnográfica, maio/2008.

SANGOÏ, J. C. Forename, family and society in southwest France (Eighteenth-Nineteenth Centurkes). Journal History of family, v. 4, issue 3, 1999.

La transmission d'un bien symbolique: le prénom, Bas-Quercy 1750-1872. Terrain, n. 4 - Famille et parenté (mars 1985) [En ligne], mis en ligne le 23 juillet 2007. Disponível em: 〈http:// terrain.revues.org/index2873.html>. Acesso em: 27 dez. 2008.

SCARPIM, F. A. Bens simbólicos em laços de pertencimento: família, religiosidade e identidade étnica nas práticas de transmissão de nomes de batismo em um grupo de imigrantes italianos (Campo Largo, PR: 1878/1937). Dissertação (Mestrado). Curitiba: UFPR, 2010.

SCHNAPPER, D. Essai de lecture sociologique. Lê prénom, mode et Histoire. Les Entretiens de Malher. Paris: Édition de L'École des Hautes Etudes em Sciences Sociales, 1980.

SMITH, D. S. Child-naming practices, kinship ties, and change in family attitudes in Hingham, Massachusetts, 1641 to 1800. Journal of Social History, n. 18, p. 541-566, 1985.

ZONANBEND, F. Prénom et identité. Lê prénom, mode et Histoire. Les Entretiens de Malher. Paris: Édition de L'École des Hautes Etudes em Sciences Sociales, 1980.

WOORTMANN, E. F. Herdeiros, parentes e compadres: colonos no sul e sitiantes no nordeste. São 
Paulo: Edunb, 1995.

\title{
Autor
}

Fábio Augusto Scarpim é doutorando do Programa de Pós-Graduação em História da Universidade Federal do Paraná (UFPR) e mestre em História. Professor assistente do Centro Universitário Campos de Andrade (Uniandrade).

\section{Endereço de correspondência}

Fábio Augusto Scarpim

Rua Cezar Scapin, 500, Caixa Postal 534 - Guabiroba Campo Largo, PR - CEP 83606-475

\begin{abstract}
Family, religiosity and ethnical identity in the practices of transmission of baptismal names in a group of Italian immigrants
\end{abstract}

The present paper has the objective of analyzing the construction of the ethnic and cultural identity of a group of Italian immigrants and their descendants who settled in Campo Largo, Paraná, Brazil, between 1878 and 1937. We assume that the identity of a group appears when inter-ethnic contact occurs or when one group feels the need to affirm itself over the others. In this context we analyzed the practices of transmission of baptismal names as signs of the construction of ethnical identity. We sought to verify how the group being studied built its identity under the guidance of the symbolic and cultural references of the land they left and how the process of change took place in view of their new realities and the cultural contacts established with the Brazilians. To guide this analyze, we based our work mainly on parish registers (records of baptisms, marriages and deaths) that were systematized by the methodology of family reconstitution, based on historical demography. This analysis enabled us to note in the baptismal names the predominance of rural traits typical of the homeland of the immigrants that symbolically linked them with the land of their ancestors. These elements were of great importance for defining the identity of the group as being both Italian and Brazilian.

Keywords: Christian names. Italian immigrants. Campo Largo.

\section{Resumen}

Familia, religiosidad e identidad étnica en las prácticas de transmisión de nombres de bautismo en un grupo de inmigrantes italianos

El presente artículo tiene el objetivo de analizar la construcción de la identidad etnocultural de un grupo de inmigrantes italianos y sus descendientes instalados en el municipio de Campo Largo (Paraná) en el periodo de 1878 a 1937. Para ello se parte del supuesto de que la identidad de un grupo étnico surge a partir del contacto interétnico, es decir, de la necesidad de afirmación de uno frente a los demás. En este sentido se analizan las prácticas de transmisión de los nombres de bautismo como signo de construcción de la identidad étnica. Se intentó verificar cómo el grupo en estudio construyó su identidad pautada por los referentes simbólicos y culturales de la tierra de partida y de qué forma ocurre el proceso de cambio, teniendo en cuenta la nueva realidad y los contactos culturales establecidos con los brasileños. Para conducir este análisis se utilizaron sobre todo registros parroquiales (actas de bautismos, matrimonios y defunciones) que fueron sistematizados por la metodología de reconstitución de familias, oriunda de la demografía histórica. Por medio del análisis de la documentación fue posible percibir en los nombres de bautismo la predominancia de elementos típicos del mundo rural de origen de dichos inmigrantes que simbólicamente los conectaban a la tierra de sus ancestrales. Estos elementos fueron muy relevantes para definir la identidad del grupo como ítalo-brasileña.

Palabras-claves: Nombres de bautismo. Inmigrantes italianos. Campo Largo. 